\title{
Chronic Administration of Rosmarinus officinalis Essential Oil Decreases Fertility in Female Rats
}

\author{
Sahel Motaghi, ${ }^{1}$ Narges Ahmadusefi, ${ }^{2}$ Bahram Shohreh, ${ }^{2}$ Mohammadnaser Nazem ${ }^{1}$ \\ 'Department of Basic Sciences, Faculty of Veterinary Medicine, Shahid Bahonar University of Kerman(SBUK), Kerman, Iran \\ ${ }^{2}$ Department of Animal Science, College of Animal Science and Fisheries, Sari Agricultural Sciences and Natural Resources University, Sari, Iran
}

Disclose and conflicts of interest: none to be declared by all authors

\begin{abstract}
Introduction: Introduction Most studies consider the useful aspects of herbal medicines, but the side effects that come with their long-term administration are not taken into account. Rosemarinus officinalis, an edible evergreen shrub from the Lamiaceae family, has long been used as a medicinal plant for its useful effects, most of which are proved scientifically. In the present study, we studied the effect that the long-term administration of $R$. officinalis essential oil has on ovaries.

Material and Methods: Female rats were divided into 4 groups, and for 21 days were injected intraperitoneally (i.p) with 0.2 ; 1 ; and $2 \%$ R. officinalis essential oil and solvent. Afterwards, the number of primordial, primary, secondary, graffian, and atretic follicles as well as the number of corpora lutea were assessed.

Results: Our results showed that the $2 \%$ concentration of $R$. officinalis essential oil decreased the number of graffian follicles and corpora lutea significantly when compared with the control group $(p<0.05)$. In addition, the number of atretic follicles showed significant increment.

Conclusion: This study suggested that the long-term administration of $R$. officinalis in food industries as a spice or preservative in animal and human nutrition should be taken with more caution.

Keywords: Rosmarinus officinalis; Ovary; Follicles; Toxicology.
\end{abstract}

\section{Introduction}

In the last years, the administration of herbal medicines has been growing fast. However, it has been shown that some of these plants may also have some adverse effects. For example, some medicinal plants such as Curcurma longa and Salvia officinalis have antifertility effects in both males and females, so they may have the potential to be used as contraceptives. ${ }^{1,2}$

Rosmarinus officinalis, an edible evergreen shrub from the Lamiaceae family, has long been used as a medicinal plant for its useful effects, ${ }^{3}$ such as antimicrobial, antiinflammatory, and antioxidant action, which are proved scientifically. ${ }^{4}$ It has also been used in the food industry as a spice and as a food preservative to prevent food poisoning. ${ }^{1}$ Antiproliferative and anticancer activity of this plant is also reported. ${ }^{3,5,6}$ There is a correlation between cell cycle and cancer because cell cycle signal pathways control cell proliferation, and cancer is a disease of inappropriate cell proliferation due to reduction in the sensitivity to signals that regulate cell adherence, differentiation, or die. ${ }^{7}$ As in the gonads, the cell proliferation and the number of cell cycles are high, and R. officinalis exerts its antiproliferative and anticancer activities via interfering in cell cycle, ${ }^{8,9}$ thus, we suspected that this plant might have some adverse effects in the gonads, including testis and/ or ovaries. In this regard, there are reports that show this plant can decrease the number of primary and secondary spermatocysts and spermatids in addition to reduction of sperm motility and density in male rats. $^{10}$ In female rats, a high incidence of anomalous rat embryos, reduced number of uterine blastocycts, ${ }^{11}$ embryo toxic effects in the preimplantation period and also no significant developmental alterations after the preimplantation period have been observed. ${ }^{12}$ In addition, this plant can inhibit the uterotropic action of estradiol and estron. ${ }^{13}$ Adverse effects of natural or synthetic chemicals on the ovaries can be defined by follicle quantitation and morphometric analysis. ${ }^{14,15}$ As the cell cycle in the germinal cells of the ovaries is short, and the antiproliferative effect of this plant is reported, for the first time we evaluated the effects of R. officinalis essential oil on a number of different kinds of ovarian follicles. The essential oil used in the present study, according to its manufactured company, was composed of $48.70 \%$ 1,8-cineole.

\section{Material and Methods}

\section{Animals}

Adult female Wistar rats weighting between 180 to $220 \mathrm{~g}$ were used for this study. The animals were kept in the animal house of the Faculty of Veterinary Medicine at the Shahid Bahonar University of Kerman, Kerman, Iran. The animals were kept in plastic cages covered with wooden chips. They had free access to 
food and water under a standard light/dark cycle. The procedures of this experiment were based on the ethical principles of international committees that protect laboratory animals (Approval No. 20/07/95).

\section{Experimental Design}

The pure essential oil of the leaf of R. officinalis was purchased from Zardband Pharmaceuticals, Tehran, Iran. The concentrations of the essential oil used in this experiment, according to a previous work13 and a pilot study, were $0.2 ; 1$; and $2 \%$. One group was determined as control and received just the solvent solution. The number of rats in each group was 7 . The solutions were prepared daily. All the injections were intraperitoneal and continued for 21 days, between 11:00 AM to 3:00 pm.

\section{Histopatological Procedures}

On day 21, the rats were sacrificed, the left ovaries were removed and fixed in 10\% buffered formalin solution. Serial sections of $5 \mu \mathrm{m}$ were prepared and stained with hematoxylin and eosin. In the sections, the ovaries were divided into 12 regions using DinoLite digital microscope, and the number of primordial, primary, secondary, antral, graffian, and atretic follicles as well as the number of corpora lutea were assessed.

\section{Morphological Classification of Follicles}

For better evaluation of the follicles, we used the Pedersen \& Peters classification: ${ }^{16}$ follicles were determined as primordial if they contained an oocyte surrounded by a partial or complete layer of squamous granulosa cells. Primary follicles showed a single layer of cuboidal granulosa cells. Follicles were determined secondary if they possessed more than one layer of granulosa cells with no visible antrum. Early antral follicles possessed generally only one or two small areas of follicular fluid (antrum), while graffian follicles possessed a single large antral space (Fig. 1). The earliest sign of atresia was the presence of $5 \%$ pyknotic granulosa cells in the largest cross section of the follicles. ${ }^{17}$

\section{Statistical Analysis}

The data was presented as mean \pm standard error of the mean (SEM). They were analyzed with one- way analysis of variance (ANOVA) and Tukey posthoc test, using the SPSS software version 22 (IBM Corp., Armonk, NY, USA). A $p$-value $<0.05$ was considered statistically significant.

\section{Results}

\section{Quantitative Evaluation of the Ovaries}

The effect of R. officinalis essential oil on a number of different types of follicles and corpora lutea is summarized in Table 1 . Our data showed that the $2 \%$ concentration of $\mathrm{R}$. officinalis essential oil decreased the number of graffian follicles and corpora lutea significantly when compared with the control group $(p<0.05)$. In addition, the number of atretic follicles showed significant increment $(p<0.05)$.
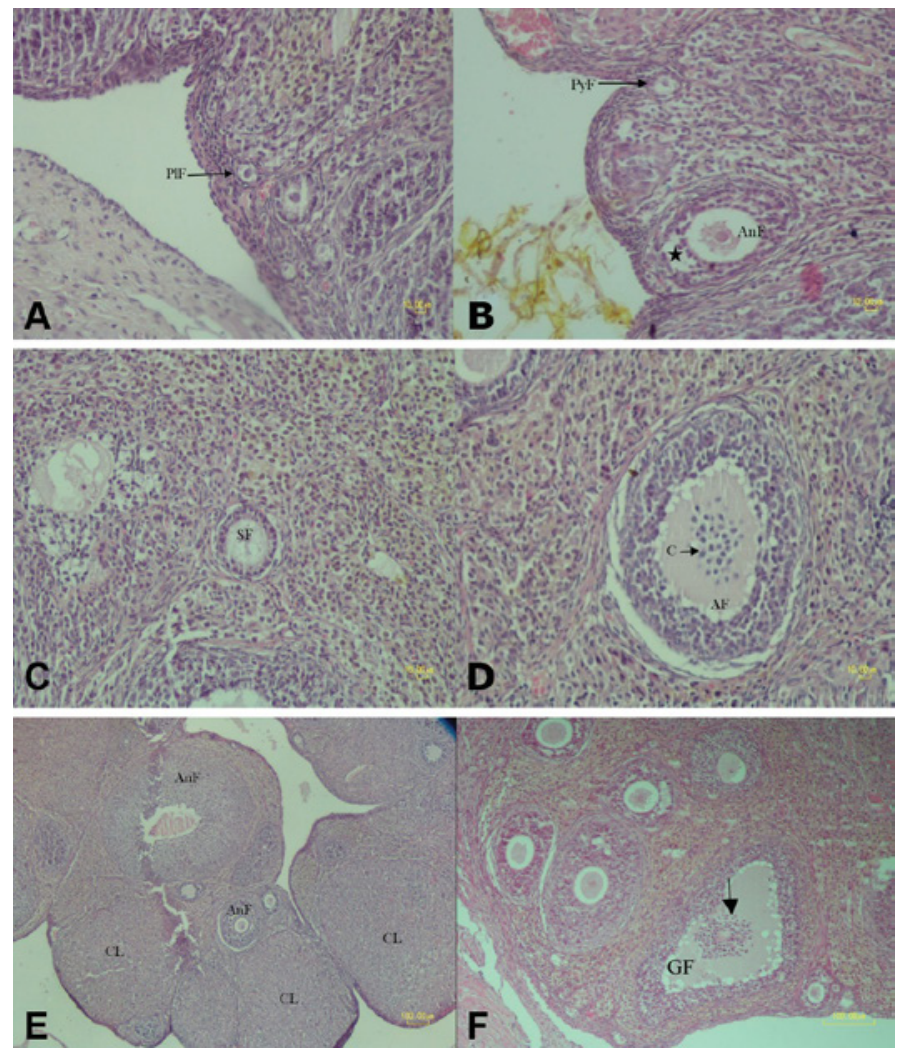

Figure 1. Different types of follicles used for analysis with hematoxylin and eosin (H\&E) staining. The numbers show the objective lens magnification. (A) Primordial follicles (PIF): they contained an oocyte surrounded by a layer of squamous granulosa cells (10), (B)Primary follicles (PyF): an oocyte with a single layer of cuboidal granulosa cells, antral follicle (AnF) which possesses a single large antral space, the star shows the antrum (10) (C) Secondary follicle (SE) with a layer of granulosa cells with no visible antrum (20) (D)asampleofatretic follicle $(A F)$, this figure shows the abnormal presence of cells (C) in the antrum (20) (E) corpus luteum (CL) and antral follicle (AnF) (4), (F) Graffian follicle (GF) have a single large antral space, the arrow shows a cumulusoophorus( 10).

Table 1. The number of different types of follicles in control and treated groups

\begin{tabular}{|c|c|c|c|c|c|c|c|}
\hline & $\begin{array}{c}\text { Primordial } \\
\text { follicles }\end{array}$ & $\begin{array}{l}\text { Primary } \\
\text { follicles }\end{array}$ & $\begin{array}{c}\text { Secondary } \\
\text { follicles }\end{array}$ & $\begin{array}{c}\text { Antral } \\
\text { follicles }\end{array}$ & $\begin{array}{l}\text { Atresia } \\
\text { follicles }\end{array}$ & $\begin{array}{l}\text { Graffian } \\
\text { follicles }\end{array}$ & $\begin{array}{l}\text { Corpus } \\
\text { luteum }\end{array}$ \\
\hline Control & $148.37 \pm 11.35$ & $107.27 \pm 8.45$ & $42.37 \pm 2.25$ & $32.21 \pm 2.84$ & $11.14 \pm 1.25$ & $7.13 \pm 1.41$ & $14.8 \pm 0.75$ \\
\hline $0.2 \%$ & $152.07 \pm 12.13$ & $104.32 \pm 9.12$ & $45.52 \pm 2.84$ & $30.75 \pm 2.53$ & $12.7 \pm 1.28$ & $6.82 \pm 1.12$ & $15.37 \pm 0.14$ \\
\hline $1 \%$ & $145.84 \pm 9.85$ & $112.57 \pm 9.47$ & $39.74 \pm 3.01$ & $31.08 \pm 2.75$ & $11.35 \pm 0.97$ & $6.92 \pm 1.25$ & $13.4 \pm 0.9$ \\
\hline $2 \%$ & $140.72 \pm 11.22$ & $113.48 \pm 8.52$ & $40.85 \pm 2.97$ & $21.08 \pm 2.31^{*}$ & $14.7 \pm 0.68^{*}$ & $2.7 \pm 0.42^{*}$ & $8.25 \pm 0.13^{*}$ \\
\hline
\end{tabular}

The number of different types of follicles in control and treated rats is presented as mean \pm standard error of the mean (SEM).

*show a significant effect compared with the control group ( $p::: 0.05)$. 


\section{Histopathological Findings}

Histologic findings in the ovaries of the animals in the control group contained graffian follicles, developing follicles, newly ruptured follicles with blood clots, corpora lutea and corpora fibrosa. The oocytes were surrounded by epithelial cells. The ovaries contained many primordial follicles, which were mostly found around the edges of the cortex under the germinal layer. Zona pellucida and granulosa cells were formed clearly. Secondary and developing follicles were also all normal with respect to their components, such as antrum, cumulus oophorus, and internal and external theca (Fig. 1). Histopathologic findings in the ovaries of the animals in the treatment group (2\%) revealed different degrees of pyknotic granulosa cells (Fig. 2D).

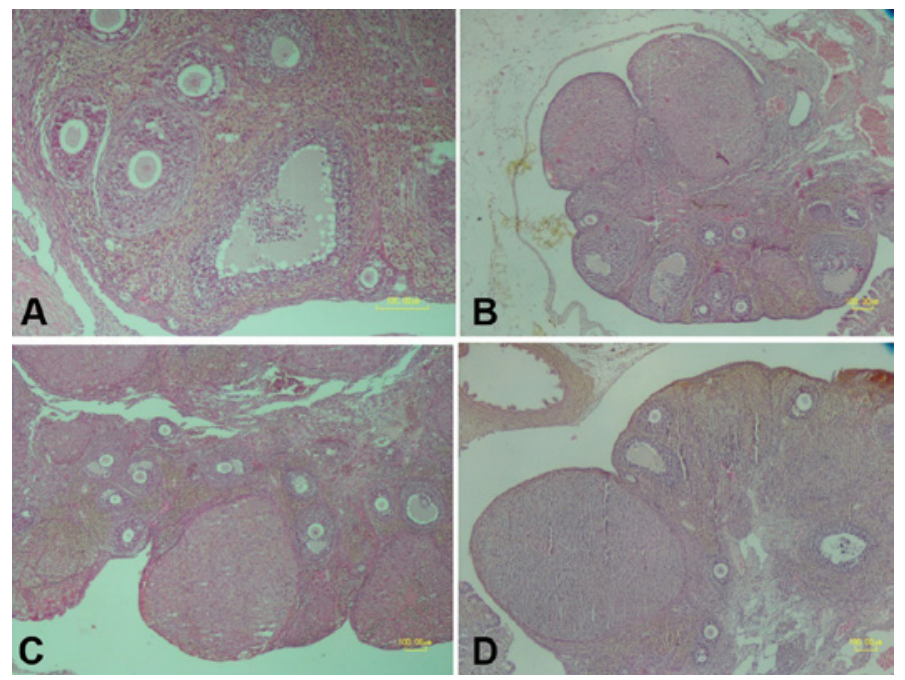

Figure 2. Histopathologic findings in control (A) and treatment groups (B): $0.2 \%$, (C): $1 \%$ and (D):2\%) with hematoxylin and eosin (H\&E) staining and the objective lens magnification: 4). The ovaries in all groups are covered by germinal epithelium. Graffian follicles, devel-oping follicles, corpora lutea and corpora fibrosa, are present in all groups. The Zona pellucida and granulosa, secondary follicles with antrum, cumulus oophorus and internal and external theca are visible in all four groups.

\section{Discussion}

The study of follicular numbers can provide important information about the function of ovaries, in particular the relationship between folliculogenesis and the factors that regulate it..$^{15}$

Ovarian toxicity can also be defined by follicle quantitation and morphometric analysis. ${ }^{18}$ Our result showed that the long-term administration of $R$. officinalis essential oil increased the number of atretic follicles. Most of the ovarian follicles undergo atresia, a hormonally-controlled apoptotic process. Atresia can occur at any stages of follicle development. ${ }^{19}$ There are many factors that prevent or help apoptosis. One of the most important factors are gonadotropins. In addition to triggering the ovulatory process, gonadotropins are required for the growth and development of ovarian follicles. Sufficient exposure of antral follicles to follicle-stimulating hormone (FSH) is the most critical stimulus for the follicles to escape atresia and reach the preovulatory (graffian) follicle stage. ${ }^{20}$ Binding of gonadotropins to their membrane receptors in granulosa cells results in the activation of adenylate cyclase, accumulation of cAMP, and, subsequently, activation of the protein kinase, which is a signaling pathway. $^{21}$ The apoptosis-suppressing action of gonadotropins is augmented by some local factors, one of which is estrogen that, in turn, prevents apoptosis by activating the nuclear estrogen receptors. ${ }^{19}$ Atretic follicles exhibit decreased estrogen production and a lower estrogen/androgen ratio in the follicular fluid, suggesting the importance of local estrogens for the maintenence of healthy follicles. ${ }^{22}$ Zhu et al, in 1998, showed that the administration of $2 \% \mathrm{R}$. officinalis extract for 3 weeks, similar to our study, made the liver increase the microsomal metabolism of endogenous estrogens. ${ }^{13}$ Our study also showed the reduction in the number of graffian follicles and corpora lutea. Estrogens are necessary for the growth and maturation of follicles. Treatment with estrogen increases the division of granulosa cells and increases ovarian weight. Therefore, the increased number of atretic follicles and decreased number of graffian follicles in this study may be related to the decreased amount of local endogenous estrogen because of its increased metabolism including, the oxidation or glucuronidation ${ }^{13}$ by the liver. There are many reports that show that $\mathrm{R}$. officinalis has antiproliferative effects. ${ }^{8,23}$ R. officinalis interfered with different phases of the cell cycle. In a study by Tai et al, in 2012, down regulation in the expression of several antiapoptosis proteins, including $\mathrm{Bcl}-2, \mathrm{Bcl}-\mathrm{x}, \mathrm{clAP}-1, \mathrm{HIF}-\mathrm{\alpha}$, and HO-1, was observed. ${ }^{9}$

The essential oil of $R$. officinalis is mainly composed of $\alpha$-pinene, 1,8 cineole and camphor. Approximately $48 \%$ of the essential oil used in the present study is constituted of 1,8-cineole, according to its manufacturer's data sheet. Eucalyptol, which is another name for 1,8-cineole, is a monoterpene oxide found in the essential oils of many herbs. This compound also has some pharmacological effects, such as antimicrobial, antiinflammatory, ${ }^{24}$ and antioxidant activity. ${ }^{8}$ There are many studies that show the antiproliferative activity of this organic component too. ${ }^{25,26}$ It is shown that 1,8-cineole inhibits cell proliferation in a dose-dependent manner, ${ }^{25}$ and its mechanism of action is via induction of apoptosis. ${ }^{27}$ Thus, the effect seen in the present study may be related to this component. In the 2016 study by Caldas et al, the chronic administration of 1,8-cineole in female rats caused reproductive toxicity, including reduction in the number of corpora lutea during the organogenesis. ${ }^{28}$ This does not happen only in females; there are also some reports that show the toxicity of R. officinalis in male rats. In this regard, Nusier et 
$a l$, in 2007, reported that ingestion of this plant, at levels of 250 and $500 \mathrm{mg} / \mathrm{kg}$ body weight for 63 days, caused a significant decline in the number of primary and secondary spermatocytes and spermatids, which is attributed to a significant decrease in testosterone. Sperm motility and density were also significantly decreased in the cauda epididymis and in the testes of rosemary-treated male rats. ${ }^{29}$

\section{Conclusion}

In the end, our results show that the long-term administration of R. officinalis may have some adverse effects on the ovaries, especially the reduced number of graphing follicles, which may lead to decreased number of offsprings in the next meeting. As the leaves of this plant are commonly used as a spice for humans and as an evergreen plant that may be consumed by domestic animals, expenditures of it should be taken into account more cautiously.

\section{References}

1. Joshi SC, Sharma A, Chaturvedi M. Antifertility potential of some medicinal plants in males: an overview. Int J Pharm Pharm Sci 2011;3(05):204-217.

2. Ghosh D, Jana D, Debnath JM. Effects of leaf extract of Stephania hernandifolia on testicular gametogenesis and androgenesis in albino rats: a dose-dependent response study. Contraception 2002;65(05):379-384.

3. Andrade JM, Faustino C, Garcia C, Ladeiras D, Reis CP, Rijo P. Rosmarinus officinalis L.: an update review of its phytochemistry and biological activity. Future Sci OA 2018;4(04):FSO283.

4. Ribeiro-Santos R, Carvalho-Costa D, Cavaleiro C, et al. A novel insight on an ancient aromatic plant: The rosemary (Rosmarinus officinalis L.). Trends Food Sci Technol 2015;45(02):355-368.

5. Jardak M, Elloumi-Mseddi J, Aifa S, Mnif S. Chemical composition, anti-biofilm activity and potential cytotoxic effect on cancer cells of Rosmarinus officinalis L. essential oil from Tunisia. Lipids Health Dis 2017;16(01):190.

6. del Pilar Sánchez-Camargo A, Herrero M. Rosemary (Rosmarinus officinalis) as a functional ingredient: recent scientific evidence. Curr Opin Food Sci 2017;14:13-19.

7. Collins K, Jacks T, Pavletich NP. The cell cycle and cancer. Proc Natl Acad Sci U S A 1997;94(07):2776-2778.

8. Amar Y, Meddah B, Bonacorsi I, et al. Phytochemicals, antioxidant and antiproliferative properties of Rosmarinus officinalis $L$ on U937 and CaCo-2 cells. Iran J Pharm Res 2017;16(01):315-327.

9. Tai J, Cheung S, Wu M, Hasman D. Antiproliferation effect of Rosemary (Rosmarinus officinalis) on human ovarian cancer cells in vitro. Phytomedicine 2012;19(05):436-443.

10. Heidari-Vala H, Ebrahimi Hariry R, Sadeghi MR, Akhondi MM, Ghaffari Novin M, Heidari M. Evaluation of an aqueous-ethanolic extract from Rosmarinus officinalis (Rosemary) for its activity on the hormonal and cellular function of testes in adult male rat. Iran J Pharm Res 2013;12(02):445-451.

11. Damasco DC, Lemonica IP. Embryotoxicity and anti-implantation effects of rosemary (Rosmarinus officinalis L.) extract in pregnant rats within preimplantation period. Rev Bras Toxicol 1999;12 (02):47-54.

12. Lemonica IP, Damasceno DC, di-Stasi LC. Study of the embryotoxic effects of an extract of rosemary (Rosmarinus officinalis L.). Braz J Med Biol Res 1996;29(02):223-227.

13. Zhu BT, Loder DP, Cai MX, Ho CT, Huang MT, Conney AH. Dietary administration of an extract from rosemary leaves enhances the liver microsomal metabolism of endogenous estrogens and decreases their uterotropic action in CD-1 mice. Carcinogenesis 1998;19(10):1821-1827.

14. Regan KS, Cline JM, Creasy D, et al; STP Ovary Evaluation Working Group. STP position paper: ovarian follicular counting in the assessment of rodent reproductive toxicity. Toxicol Pathol 2005;33(03):409-412.

15. Myers M, Britt KL, Wreford NG, Ebling FJ, Kerr JB. Methods for quantifying follicular numbers within the mouse ovary. Reproduction 2004;127(05):569-580.

16. Pedersen T, Peters H. Proposal for a classification of oocytes and follicles in the mouse ovary. J Reprod Fertil 1968;17(03): 555557

17. Greenwald GS, Roy SK In: Knobil E, Neil JD, eds. Follicular development and its control. Ravan Press; 1994:629-724.

18. Smith BJ, Plowchalk DR, Sipes IG, Mattison DR. Comparison of random and serial sections in assessment of ovarian toxicity. Reprod Toxicol 1991;5(04):379-383.

19. Kaipia A, Hsueh AJ. Regulation of ovarian follicle atresia. Annu Rev Physiol 1997;59(01):349-363.

20. Chun SY, Eisenhauer KM, Minami S, Billig H, Perlas E, Hsueh AJW. Hormonal regulation of apoptosis in early antral follicles: folliclestimulating hormone as a major survival factor. Endocrinology 1996;137(04):1447-1456.

21. Leung PCK, Steele GL. Intracellular signaling in the gonads. Endocr Rev 1992;13(03):476-498.

22. Williams PC. Effect of stilbestrol on ovaries of hypophysectomized rats. Nature 1940;145:388-389.

23. Kontogianni VG, Tomic G, Nikolic I, et al. Phytochemical profile of Rosmarinus officinalis and Salvia officinalis extracts and correla- tion to their antioxidant and anti-proliferative activity. Food Chem 2013;136(01):120-129.

24. Juergens LJ, Racké K, Tuleta I, Stoeber M, Juergens UR. Antiinflammatory effects of 1, 8-cineole (eucalyptol) improve glucocorticoid effects in vitro: A novel approach of steroid-sparing add-on therapy for COPD and asthma? Synergy 2017;5:1-8.

25. Rodenak Kladniew B, Polo M, Montero Villegas S, Galle M, Crespo R, García de Bravo M. Synergistic antiproliferative and anticholesterogenic effects of linalool, 1,8-cineole, and simvastatin on human cell lines. Chem Biol Interact 2014;214:57-68.

26. Murata S, Shiragami R, Kosugi C, et al. Antitumor effect of 1, 8cineole against colon cancer. Oncol Rep 2013;30(06): 2647-2652. 27. Moteki H, Hibasami H, Yamada Y, Katsuzaki H, Imai K, Komiya T. Specific induction of apoptosis by 1,8-cineole in two human leukemia cell lines, but not a in human stomach cancer cell line. Oncol Rep 2002;9(04):757-760.

28. Caldas GF, Limeira MM, Araújo AV, et al. Repeated-doses and reproductive toxicity studies of the monoterpene 1,8-cineole (eucalyptol) in Wistar rats. Food Chem Toxicol 2016; 97:297-306. 29. Nusier MK, Bataineh HN, Daradkah HM. Adverse effects of rosemary (Rosmarinus officinalis L.) on reproductive function in adult male rats. Exp Biol Med (Maywood) 2007;232(06):809-813. 